\title{
Exploration of Online Education Mode for Postgraduate Education under the Background of COVID-19
}

\author{
Yan Li*, Xiaoqing Wen*, Liqing Li, Yan-E Zhou, Longjian Huang, Bo Ling, Xianjiu Liao\#, \\ Qianli Tang\#
}

Youjiang Medical University for Nationalities, Baise, China

Email: "lxj2006910@163.com, ${ }^{* h t m g x 919 @ 163 . c o m ~}$

How to cite this paper: Li, Y., Wen, X. Q., Li, L. Q., Zhou, Y., Huang, L. J., Ling, B., Liao, X. J., \& Tang, Q. L. (2021). Exploration of Online Education Mode for Postgraduate Education under the Background of COVID-19. Advances in Applied Sociology, 11, 223-230.

https://doi.org/10.4236/aasoci.2021.115019

Received: March 21, 2021

Accepted: May 4, 2021

Published: May 7, 2021

Copyright $\odot 2021$ by author(s) and Scientific Research Publishing Inc. This work is licensed under the Creative Commons Attribution International License (CC BY 4.0).

http://creativecommons.org/licenses/by/4.0/

\begin{abstract}
Objective: This paper explores the application of online education mode for a postgraduate teaching education and its influence on postgraduate development under the background of COVID-19. Methods: This paper discusses the innovation modes of various online education platforms in postgraduate teaching, and analyzes the influence of online education in postgraduate curriculum education and academic ability education. Results: After the outbreak of COVID-19, online teaching methods are more abundant and innovative content is more, which stimulated the learning enthusiasm of postgraduates. Online platforms provide more opportunities for academic exchanges among postgraduates, which helps to improve the teaching quality of postgraduates. Conclusion: Online education has gradually developed into a more effective and potential education method. Combined with the application status of online teaching mode in postgraduate education, this paper provides specific development suggestions for universities and colleges to further construct and develop high-quality online teaching mode for postgraduates.
\end{abstract}

\section{Keywords}

Postgraduate Education, COVID-19, Educational Reform, Online Education, Academic Lecture

\section{Introduction}

The outbreak of COVID-19 brings new challenges to the education and teaching

*: These authors contributed equally to this work.

\#: Corresponding authors. 
of postgraduates in universities and colleges. Universities and colleges have started online teaching mode to ensure the smooth progress of education. At the same time, with the gradual maturity of new media technology, the development of online teaching platform brings a good entry point for the reform of postgraduate education, which can promote the innovation of teaching methods, deepen the reform of postgraduate teaching mode, and further improve the teaching quality and talent development quality of postgraduate education in universities and colleges.

Postgraduate education marks the highest level of education in China, the engine of building a powerful education country, and the main way to cultivate innovative talents. Therefore, the mode and quality of postgraduate education have been paid much attention by the country. The education of postgraduates focuses on training their innovative thinking and independent learning ability, enhancing their comprehensive ability to discover, analyze and solve problems, and cultivating their ability to scientific research. However, the filling of boring knowledge in the traditional classroom is not suitable for the cultivation of innovative talents in universities and colleges. The combination of "Internet + Higher Education" has created various new teaching modes, which has made up for the deficiency of traditional teaching modes. Online teaching breaks through the limitation of space, enables postgraduates to devote themselves to learning anytime and anywhere, and makes the talent development mode more flexible and diverse, which is conducive to the all-round development of talents. The occurrence of COVID-19 will further promote the development of online education. Online education mode will become an inevitable trend of higher education reform.

\section{Combination of Online Teaching Platform and Classroom}

Online teaching platform is a cloud service platform based on mobile Internet and smart mobile devices to provide interactive teaching for teachers and students. With the combination of online teaching platform and traditional classroom, teaching methods are more abundant, innovative content is more, and class atmosphere is active. At present, popular intelligent online teaching tools such as "Mosoteach", "Rain Classroon" and "Duifene" are well integrated into traditional classes. Researches show that the class with the combination of online platform can significantly improve the performance of students with high participation (Wang, Tao, Atikaimu et al., 2020).

The innovative content of online teaching platform is reflected in the following aspects. The first is "classroom attendance". Traditionally, the attendance method is to check the list of students for roll call, while the online platform can provide different mobile phone check-in modes. Teachers only need to simply publish the check-in task, and students can easily check-in on their mobile phones, which effectively save classroom teaching time and helps to improve student attendance ( $\mathrm{Li}, \mathrm{Zhu}, \& \mathrm{Wu}, 2019)$. The second is "classroom interac- 
tion". The traditional interaction is to choose individual students to answer questions. Now, the online platform can be used to select students randomly, which avoids the subjective choice of teachers. In addition, for example, Mosoteach Platform has also designed "raise your hand" and "rush to answer" links. Teachers can reward students who actively answer questions in class with points, which can more effectively enliven the teaching atmosphere of the class (Jia, Li, \& Tang, 2019). It can also issue open question thinking on the online platform as classroom question, and let the whole class do the limited time choice questions or short answer the small questions of pioneering thinking. This can not only master the students' mastery degree and application degree of classroom knowledge, but also serve as a turning point to lead to the next new content in the classroom, so as to enrich the form of class. At the same time, it can grasp the attention of the students so that the whole class can participate. The third is "curriculum discussion". In traditional classroom discussion, teachers put forward thinking questions to arouse students' discussion. However, due to limited seats, the number of participants is small and students are not motivated to discuss, especially in large classes (Yang, Zhang, Sun et al., 2020). Classroom discussions on the online platform can be discussed in groups, and then each group selects a representative to speak. The teacher analyzes and comments on the group's answers, and rewards the group with good answers with points. Class discussion can inspire students' thinking, stimulate their interest in learning, and effectively improve the quality of classroom teaching. The mobile phone can be transformed from a distracting entertainment tool into a learning tool in the classroom, allowing students to maximize their input and participation in learning.

\section{After-School Application of Online Platform}

Postgraduate education after class is mainly student-centered independent learning, and subject teachers and supervisors can guide through online teaching platform. At the same time, the online teaching platform can provide rich teaching resources, so that postgraduates can really "anytime, anywhere, keep" learning after class, and arrange their time more freely and reasonably in the limited time; change mobile phone into learning tool to improve learning efficiency and effect.

On the one hand, after class, postgraduates can use the online platform to view the teacher's courseware and video anytime and anywhere, complete the relevant exercises, and test the personal absorption of classroom knowledge (Yang, Zhang, Sun et al., 2020). Designing question banks with different levels of difficulty to practice knowledge points is also conducive to teaching students in accordance with their aptitude. According to each student's mastery of knowledge points, different types of questions with different degrees of difficulty are selected. Students with better knowledge absorption can further improve themselves. Students with poor receptive ability need to continue to consolidate their 
knowledge through exercises. At the same time, in the traditional mode, the relationship between teachers and students is mechanical, and the contact between teachers and students is very limited, which is not conducive to further communication between teachers and students. In the innovative teaching mode, teachers can answer questions for students online through the platform (Zhang, Chen, Chen et al., 2020) to increase the interaction after class. The platform can also provide data analysis, so that teachers and supervisors can understand students' knowledge mastery in real time (Wang, Tang, Peng et al., 2019), contact students and provide personalized suggestions and guidance.

On the other hand, because they carry out scientific research practice in grade two and grade three, postgraduates can use online education platform to get cutting-edge knowledge related to professional fields pushed by supervisors and online academic lectures to expand students' scientific research ideas, exercise their scientific logical thinking, and promote them to master scientific research practice methods solidly. Teachers can also use more heuristic teaching content to cultivate students' thinking habit of thinking more and using their brain frequently, so as to lay a foundation for postgraduates to engage in scientific research and management independently (Niu \& Wang, 2018). In addition, through the online platform, the scientific research group can hold regular seminars, or hold online meetings to explain literature and share the skills of literature reading and writing, so as to provide a good platform for the cultivation of postgraduates' language expression ability (Chen, Zhang, Jia et al., 2021).

\section{Online Academic Lectures}

Attending academic lectures is an important way to know about the relevant academic frontiers in professional fields quickly and directly. And the academic lecture is not only a new approach of talent development in postgraduate education, but also a model of postgraduate training to expand professional knowledge.

Academic lectures help postgraduates know about the frontier knowledge of their professional disciplines, broaden their academic vision, enrich their academic knowledge, and encourage them to conduct scientific research and academic innovation. Therefore, in order to improve the quality of postgraduate talent development, various universities and colleges constantly organize different leading academic lectures, expecting to deepen academic exchange of postgraduates. It is studied that the academic lectures exert a significantly differential influence upon the academic development of postgraduates who attend the lectures differently (Tian, 2019).

At present, with the influence of internet technology, there are an increasing number of online academic lectures. In contrast, there existing some problems in the traditional offline academic lectures, such as low participation and learning initiative of postgraduates, the limited audiences of lectures and lacking of openness of academic lectures in universities and colleges. Online academic lec- 
tures, in the form of "cloud video broadcast", have broken through the limitation of location and widely acclaimed due to its novel form, strong interaction, wide audience and good effect. In addition, it is more convenient for audiences to attend academic lectures with a WeChat link or online communication software such as "Tencent Meeting" and "DingTalk", saving staff and space. During the outbreak of COVID-19, online lectures became the best and safest way for academic exchange.

It is favorable for postgraduates to acquire the information when attending online academic lectures, because the speaker's facial expressions and body movements can be closely observed through the screen which attracts their attention, so they better absorb the content of academic exchanges. In this environment of free academic discussion, more communication and interaction can be added to online mode to activate the atmosphere of academic exchanges and actively guide the ideological collision between the seniors and the newcomers in the academic circles, which can not only enrich the academic knowledge of postgraduates, but also provide them with more academic exchange opportunities, and offer academic experts some new ideas about scientific research. At the same time, because some postgraduates have resistance to classroom teaching mode, they desire for novel and diverse lecture exchanges to improve the impact on their academic development (Heng, Feng, \& Wang, 2018). And there are differences between the rich and varied online lectures and the traditional and fixed one. However, this can increase the initiative of postgraduates, guide them to think actively, improve the absorption effect on the academic content of lectures, and develop the creative thinking in scientific research. Therefore, more and more teachers and students favor the academic exchange mode of "live communication + online interaction" (Tian, 2019).

\section{Suggestions}

Online education provides a new teaching method, which integrates the educational philosophy of "teachers-oriented" replaced by "students-oriented" with Internet technology. Nowadays, with the gradual popularization and maturity of online learning platforms for postgraduates, new media technology provides a new development path for postgraduate education in universities and colleges (Zhang \& Tian, 2021). However, there existing some challenges while the new online education has brought new opportunities to the teaching mode and philosophy of modern education. At present, this education mode is still in the exploratory stage, and some suggestions are as follows.

\subsection{Training of Teachers}

In the era of "Internet Plus Education", teachers need to keep pace with the development of new technology and have the awareness of using information technology. Especially in the context of the pandemic, online education has become an indispensable teaching mode. However, in the teaching practice of uni- 
versities and colleges, most teachers have been accustomed to the traditional offline teaching mode, so they have not done a good job in the curriculum construction of online teaching. And they did not use the online teaching platform as the auxiliary and supplement to traditional teaching before the pandemic. Therefore, in order to ensure the quality of online teaching, universities and colleges need to provide systematic teaching training for teachers, especially for those who accept the Internet technology slowly.

\subsection{Unified Online Teaching Platform}

Nowadays, there are a great variety of online education platforms with different features and functions. However, due to different courses, students download multiple online education software on their mobile phones or computers, and need to adapt to different online platforms at the same time, which is a burden for them. Therefore, in order to ensure the teaching goes smoothly, it is suggested that universities should establish their own online platform and maintain it regularly, or students of each major should use a unified online teaching platform.

\subsection{Online Scientific Research Platform}

Putting students first, the online education platform plays a very important role in the teaching system of postgraduates. Therefore, it is necessary to know precisely the learning needs of students, train the scientific ideas of postgraduates, exercise their scientific research practice ability, and learn scientific reasoning and summary methods ( $\mathrm{Li}, \mathrm{Zhu}, \& \mathrm{Wu}, 2019)$. Therefore, the ability of postgraduates in this aspect needs to be cultivated in the innovation and reform of online education platform.

At present, with fewer contents and frequency of experimental teaching, both online and offline postgraduate education place extra emphasis on theoretical study, rarely using experimental equipment in scientific research projects, and having few opportunities to repeat experimental exercises. As a result, postgraduates are lack of subjective initiative and good scientific research thinking, and it is difficult for them to put the learned experimental methods into practice in the future scientific research, not qualified for the actual work requirements. Therefore, more 3D simulation operation practice of online professional practice can be designed on online education platform, such as simulation operation of medical surgery and sophisticated instrument operation. Although the online simulation does not replace the real operation, it can make postgraduates more familiar with the experimental operation and make up for the deficiencies in the real teaching.

Furthermore, in addition to such ways as the direct teaching by teachers and consulting the literature, the postgraduates can study and explore scientific experimental methods through the internet platform including "emuch.net" and "Bilibili". These are mainly individual opinions, which are somewhat misleading. 
Therefore, it is encouraged to establish a systematic and standardized online operation platform for scientific research experiments, providing a wide range of postgraduates correct guidance in scientific research, and reducing detours caused by misdirection.

\subsection{Online Academic Exchange Platform}

In the future, online academic lectures will become the primary tool for students to obtain academic exchanges, especially for postgraduates. At present, the constant reform and development are needed for online lectures to achieve better academic exchange; therefore, it is necessary to improve the publicity of lectures, especially the high-quality academic exchange lectures to avoid the low participation among postgraduates; universities and colleges need to organize the project and curriculum construction of online academic lectures; it is encouraged to establish an online platform to collect open academic lectures related to professional fields and remind postgraduates to attend, in which postgraduates can selectively participate according to their professional relevance and research interests.

\section{Conclusion}

To sum up, the design concept of online education platforms is to change the traditional single education mode and enrich teaching methods. Compared with traditional teaching, online teaching as a new teaching mode can greatly promote education reform and improve the overall quality of postgraduates. With the development of Internet new media technology and the impact of COVID-19, online platform education is becoming more and more important for postgraduate. And it will become an indispensable teaching method for their education, which should be vigorously promoted and popularized. However, online teaching is not a substitute for traditional education, but a reflection of the diversity of teaching modes. The traditional classroom teaching method of offline education still has its own strength ( $\mathrm{Li}, \mathrm{Li}$, \& Zhao, 2020), and the online education mode is still growing in exploration. There is an increasing trend that the dual form of "online and offline" teaching mode will be adopted to complete postgraduate education with higher quality.

\section{Fund Program}

Innovation Project of Guangxi Postgraduate Education (Project No. JGY2020170, JGY2019161, JGY2021219); construction project of case bank for professional degree postgraduate teaching in Youjiang Medical University for Nationalities (Project Name: Case Bank Construction of Surgery Teaching).

\section{Conflicts of Interest}

The authors declare no conflicts of interest regarding the publication of this paper. 


\section{References}

Chen, L. J., Zhang, Z., Jia, L. Q. et al. (2021). Thoughts on the Online Training Mode of Scientific Research Ability for Graduate Students of Traditional Chinese Medicine Hospitals under the Background of the Epidemic. Health Vocational Education, 39, 9-11.

Heng, X. H., Feng, M., \& Wang, D. (2018). Advantages and Disadvantages of Academic Lectures for Postgraduates. Literature Education (II), 11, 147-148.

Jia, H. J., Li, Y. Y., \& Tang, Y. L. (2019). Assessment and Reform Method of Mosoteach Based on Mobile APP. Computer Education, 5, 137-141.

Li, J., Zhu, J. M., \& Wu, S. (2019). Application of Mosoteach on the Postgraduate Teaching of Medical Statistics. Science Education Article Collects, 461, 90-91, 98.

Li, Y. B., Li, H., \& Zhao, B. H. (2020). Live Broadcast Teaching Method for Postgraduates-Taking Hebei Agricultural University as an Example. China Education of Light Industry, 3, 39-42.

Niu, X. K., \& Wang, Z. Z. (2018). Exploration of Hybrid Teaching Mode of Intelligent Control Postgraduate Course. Science and Technology Innovation Herald, 15, 137-140.

Tian, X. F. (2019). Study on the Impact of Academic Lectures on the Academic Development of Postgraduates in Colleges and Universities-A Survey of Graduate Students from $H$ University. Changsha, Hunan: Hunan Normal University.

Wang, M. Q., Tang, X. H., Peng, J. H. et al. (2019). Application of Nursing Clinical Ladder Program Based on Benner Theory in Nurses' Stratified Training. Chinese Journal of Practical Nursing, 35, 142-146.

Wang, Q., Tao, N., Atikaimu, W. et al. (2020). Innovation and Practice of Rain Classroom in Clinical Epidemiology. China Medical Education Technology, 2, 206-208, 213.

Yang, C. M., Zhang, X., Sun, M. S. et al. (2020). Rain Classroom Based Case Study of Flipped Classroom in a Large Class for Graduate Students. Academic Degrees \& Postgraduate Education, 7, 45-50.

Zhang, H., Chen, X. X., Chen, M. D. et al. (2020). Analysis on the Online Teaching Experience of Post-Graduates. Science Education Article Collects (Mid-Issue), 9, 53-54.

Zhang, J., \& Tian, D. (2021). Research on the Guidance of New Media Technology to Postgraduate Education. Teaching and Educating People (Higher Education Forum), 3, 16-18. 